\title{
LA HISTORIA OCULTA DE EDUCO Y SUS RESULTADOS DESCONOCIDOS: CONEXIONES ENTRE EDUCO, EL APODERAMIENTO COMUNITARIO Y LA GUERRA CIVIL EN EL SALVADOR
}

\author{
D. Brent Edwards Jr. \\ University of Hawaii, Manoa \\ dbrente@gmail.com \\ Marcel Pagès \\ Universitat Autònoma de Barcelona \\ marcel.pages@uab.cat
}

Recepción:

21 de julio de 2017

Aceptación:

25 de agosto de 2017 


\section{RESUMEN}

El programa "Educación con Participación de la Comunidad" (EDUCO), desarrollado en El Salvador durante los años 90 y 2000 , consiguió fama internacional con un diseño que otorgaba a las familias la capacidad de despedir y contratar a los maestros a nivel de la comunidad. A pesar de la atención que ha recibido dicho programa, muchos aspectos clave de su trayectoria e impacto han sido subestimados. En este artículo se ofrece una reinterpretación de EDUCO al explicitar la emergencia de este programa, su historia oculta y sus resultados menos conocidos. Como se demuestra, EDUCO no solo emergió antes de terminar la guerra gracias a la actividad política del partido conservador ARENA, sino también debido al rol de organizaciones internacionales como la USAID (Agencia de Desarrollo Internacional de los EEUU), UNESCO (Organización de las Naciones Unidas para la Educación, la Ciencia y la Cultura) y el Banco Mundial. En relación a la implementación del programa, el artículo muestra como la práctica y el funcionamiento del programa estuvieron caracterizados por numerosas limitaciones y efectos adversos. El análisis presentado nos ofrece una reinterpretación de EDUCO cuyo valor radica en la posibilidad de estimular una forma diferente de pensar acerca de las relaciones entre la educación, el desarrollo comunitario y la guerra civil.

\section{Palabras Clave \\ EDUCO, USAID, Banco Mundial, Gestión}

Comunitaria, Guerra Civil

\section{ABSTRACT}

The "Education with Community Participation" (EDUCO) program in El Salvador achieved international fame in the late 1990s and 2000s with its design which formally transferred the ability to hire and fire teachers to a committee of parents at the community level. Despite the significant attention this program has received, there are several key aspects of its trajectory and impact that has been underappreciated. The reconsideration offered in this paper is made possible by revealing the hidden history and the unknown outcomes of EDUCO. As is shown, EDU$\mathrm{CO}$ not only emerged before the end of the civil war, thanks to the political activity of the conservative party (ARENA), but also due to the role of international organizations such as USAID (the United States Agency for International Development), UNESCO (the United Nations Education, Science, and Culture Organization), and the World Bank. Regarding the implementation of the program, the article shows how the practical operation of the program was characterized by many limitations and numerous negative side effects. The analysis offers a reinterpretation of EDUCO which is valuable because it encourages us to think anew about the enduring relationship among education, community development, and civil war.

\section{Keywords}

EDUCO, USAID, World Bank, communitybased management, civil war 


\title{
LA HISTORIA OCULTA DE EDUCO Y SUS RESULTADOS DESCONOCIDOS: CONEXIONES ENTRE EDUCO, EL APODERAMIENTO COMUNITARIO Y LA GUERRA CIVIL EN EL SALVADOR
}

\author{
D. Brent Edwards Jr. \\ University of Hawaii, Manoa \\ dbrente@gmail.com
}

Marcel Pagès

Universitat Autònoma de Barcelona Marcel.pages@uab.cat

El programa "Educación con Participación de la Comunidad" (EDUCO), desarrollado en El Salvador en los años 90 y 2000, consiguió fama internacional debido, entre otras cosas, a la capacidad que otorgó a los padres de familia de despedir y contratar a los maestros a nivel de la comunidad. Si bien la literatura reciente se ha centrado en la trayectoria de EDUCO y en su entrada en la agenda educativa internacional, convirtiéndose en una "política educativa global", hay aún aspectos centrales de la experiencia de EDUCO que restan desconocidos o que han sido subestimados por los profesionales de la educación, los responsables políticos y los especialistas en desarrollo internacional. Es importante destacar estos aspectos "invisibles" de EDUCO porque nos permiten mirar su historia desde una perspectiva diferente. En otras palabras, el valor de una reinterpretación de EDUCO radica en la posibilidad de estimular una forma diferente de pensar acerca de las relaciones entre la educación, el desarrollo comunitario y la guerra civil. 
Así, mientras el propósito principal de este artículo es ofrecer una reinterpretación de EDUCO, también se plantean dos objetivos más específicos. El primero es revelar la historia oculta de EDUCO, un programa que empezó antes del fin de la guerra civil y que pudo emerger debido a un conjunto de desarrollos políticos y económicos que tuvieron lugar durante los años 80, como por ejemplo la intervención de la USAID, en gran parte desconocida. Tal y como será discutido a continuación, una contribución de esta historia oculta para el presente número monográfico de la Revista de Humanidades y Ciencias Sociales, es mostrar que EDUCO - el programa de reforma educativa más influyente en el contexto de post-guerra - no fue del todo influenciado por el proceso de paz ni por el proceso oficial de formación de la política educativa que ocurrió después de la firma de los Acuerdos de Paz en 1992.

El segundo objetivo de este artículo es clarificar como - y con qué implicaciones - EDUCO operó a la práctica. Queremos alcanzar esta tarea presentando los hallazgos del funcionamiento de EDUCO, que emergen del análisis de un conjunto de evaluaciones e investigaciones cualitativas. Dicho otro modo, en vez de centrarse en los estudios cuantitativos promovidos por el Banco Mundial que hicieron famoso el programa EDUCO, este artículo se centra en un conjunto de estudios, generalmente desconocidos, sobre el funcionamiento practico de EDUCO en el ámbito comunitario. A pesar de que los estudios del Banco Mundial son brevemente abordados a continuación, el interés de este artículo radica, en parte, en la revisión de la literatura cualitativa, que nos ofrece una imagen más matizada sobre la implementación de EDUCO y nos permite reconsiderar los significados e implicaciones de este programa.

En términos teóricos, los resultados presentados en las dos primeras secciones del artículo se basan en la perspectiva de la economía política internacional, tomada como un enfoque que nos permite entender la evolución y emergencia de la política educativa. Brevemente, esta perspec- 
tiva teórica dirige su atención a las condiciones estructurales, políticas y económicas que limitan o condicionan el desarrollo de un proceso político. Desde este punto de vista, esta perspectiva se centra, entre otras cosas, en el rol de las organizaciones internacionales y los mecanismos a través de los cuales estas organizaciones influencian el diseño y la difusión de las políticas. Metodológicamente, los resultados presentados y discutidos en las dos primeras secciones son producto de un trabajo completado a lo largo de ocho años (2009 - 2017). La primera parte del artículo, sobre la historia de EDUCO, emerge de un estudio de caso llevado a cabo durante varios años, sobre los orígenes y la trayectoria de esta política a partir de análisis de documentos y 157 entrevistas con actores a nivel local, nacional y supranacional, de relevantes organizaciones internacionales y gubernamentales ${ }^{1}$. La segunda parte del artículo, sobre el funcionamiento práctico de EDUCO, es el resultado de una revisión crítica de la evidencia sobre EDUCO.

Las siguientes dos secciones se corresponden con el primer propósito mencionado. Específicamente, la primera sección presenta el contexto histórico de El Salvador y los cambios estructurales que ocurrieron durante la guerra civil, los cuales abrieron un espacio para la emergencia de EDUCO. La segunda sección revela en detalle el proceso oculto en el cual emergió EDUCO. La tercera sección, cambia el foco para abordar el segundo objetivo mencionado anteriormente, ofreciendo una idea sobre el funcionamiento de EDUCO, en base a una revisión de estudios que son dificiles de encontrar, incluso dentro de El Salvador, y que son casi desconocidos fuera del país. El artículo concluye con una discusión y reflexión sobre el significado de estos aspectos ocultos de EDUCO - en su historia y

1 Para saber más, ver: D.B. Edwards Jr., «The trajectory of global education policy: Community-Based Management in El Salvador and the global reform agenda» (New York: Palgrave MacMillan, próximamente).

Edwards, Jr., J.Victoria y P Martin, «Corrientes internacionales, desarrollos estructurales, preferencias nacionales y la implementación de políticas educativas: Hallazgos en El Salvador durante el periodo 1990-2005", Journal of Supranational Policies of Education, 2, (2014), 111-140. 
en su implementación - con el fin de establecer paralelos entre el conflicto armado, la posguerra y la situación actual.

\section{Contexto histórico y transformación estructural de el salvador an- tes de $\mathrm{EDUCO}^{2}$}

Para contextualizar el surgimiento de EDUCO es imprescindible retroceder hacia los años ochenta, a modo de comprender la estructura económica y política de la época. En la década de los ochenta El Salvador se encuentra sumido en un conflicto civil que fue desencadenado por el choque entre (a) una población desconforme con la reforma agraria y la abolición de tierras comunales y ejidales y (b) un gobierno en alianza con una oligarquía económica que, en conjunto, y con apoyo de las Fuerzas Armadas, reprimía esta oposición. La represión ejercida por las Fuerzas Armadas a través de los escuadrones de la muerte, se tradujo, para 1983, en un aproximado de 40,000 muertos ${ }^{3}$. Esta situación de miseria y abuso llevó a cinco grupos sociales a tomar las armas y constituirse en el Frente Farabundo Martí para la Liberación Nacional (FMLN), un grupo revolucionario de ideología socialista, constituido para luchar contra la situación de opresión. Estas cinco organizaciones político-militares eran conocidas como Fuerzas Populares de Liberación, Resistencia Nacional, Ejército Revolucionario del Pueblo, Partido Comunista Salvadoreño y Partido Revolucionario de los Trabajadores Centroamericanos $^{4}$

\footnotetext{
2 Esta y la siguiente sección ha sido adaptada de D.B. Edwards Jr. y C. Loucel, «El programa EDUCO, las evaluaciones de impacto y la economía política de la reforma educativa global"», Archivos Analíticos de Políticas Educativas, 24 (49), (2016), 1-50. Disponible en: http://epaa.asu. edu/ojs/article/viewFile/2019/1821

3 R.C. Orr, Building peace in El Salvador: From exception to rule. Peacebuilding as politics: Cultivating peace in fragile societies (Colorado, USA: Lynne Rienner Publishers, Inc., 2001), 153-182. 4 T. Montgomery, «Revolution in El Salvador: From civil strife to civil peace» (Westview: Boulder, 1995).
} 
De forma simultánea - y en el contexto de la Guerra Fría-, la guerra civil que se desataba en El Salvador se volvió un conflicto de especial interés para Estados Unidos, pues no quería que grupos socialistas-ni en El Salvador ni en Nicaragua - controlaran los gobiernos centroamericanos. Por esa razón, el gobierno de los Estados Unidos envió cantidades significantes de apoyo militar y social al país. Para poner en perspectiva la magnitud de la ayuda provista por Estados Unidos, se considera que entre 1963 y 1979 el monto de ayuda fue de 150 millones de dólares, mientras que entre 1980 y 1992, el monto ascendió a 6 billones aproximadamente ${ }^{5}$. Para 1985, el monto de apoyo dirigido exclusivamente para las fuerzas armadas salvadoreñas fue de 533 millones de dólares. ${ }^{6}$

Además, es importante señalar que, durante los años ochenta, la administración del Presidente Reagan en los Estados Unidos se dedicaba a la promoción e implementación de políticas económicas neoliberales. En términos de El Salvador, la USAID percibió que esta época era el momento oportuno para dirigir al país hacia políticas económicas de su interés. Para ello, además del fuerte apoyo militar, Estados Unidos dedicó fondos a acciones políticas, económicas y sociales. Con esta estrategia, la USAID fortaleció la creación de "nuevos agentes económicos" afines a la apertura del país hacia políticas neoliberales, bajo el propósito de contrarrestar la influencia de los actores políticos salvadoreños de ese tiempo, que no compartían los mismos intereses y preferencias por una reforma política que privilegiara un sistema económico neoliberal ${ }^{7}$. En particular, la USAID vio como obstáculo la administración del presidente populista José Napoleón Duarte, a quien

5 W. Robinson, «Transnational conflicts: Central America, social change, and globalization» (New York:Verso, 2003), 89.

6 J. Booth, C. Wade and T. Walker, «Understanding Central America» (Boulder, CO:Westview Press, 2006), 105.

7 W. Robinson, «Transnational conflicts: Central America, social change, and globalization» 
el Congreso de los Estados Unidos se sintió forzado a apoyar para lograr la estabilidad del país frente a la guerra civil ${ }^{8}$.

Parte de la estrategia elaborada por los Estados Unidos consistió en la creación de organizaciones de carácter político y social que garantizaran la presencia del pensamiento neoliberal dentro del país. A tal fin, en 1983, la USAID facilitó la creación de la Fundación Salvadoreña para el Desarrollo Económico y Social (FUSADES), un espacio destinado al establecimiento de líneas estratégicas para las políticas económicas, políticas y sociales. Así, FUSADES se convertiría en el tanque de pensamiento ("think tank") de economistas afines a las preferencias políticas de los Estados Unidos. Mientras FUSADES era un espacio para recibir a famosos economistas internacionales y aprender de ellos, también fue un espacio clave para levantar el perfil de economistas, hombres de negocio y políticos salvadoreños que concordaban con la perspectiva económica de USAID. Para dimensionar la importancia de FUSADES en función de los intereses de Estados Unidos, se puede subrayar que la USAID otorgó a esta institución contratos con un valor de 150 millones de dólares entre 1983-1993.

Para 1986, también se crea la Fundación Empresarial para el Desarrollo Educativo (FEPADE), otra apuesta realizada a través de USAID, pero en este caso, enfocada a la educación. En este contexto, la FEPADE se encargó de capacitar y formar técnicos especialistas que, desde un pensamiento conservador, diagnosticaran las necesidades del sector educativo. Dado su origen y orientación, la FEPADE era una fuente de capacidad técnica clave para USAID y el gobierno salvadoreño, particularmente durante los años noventa, cuando el partido de derecha asumió el poder. Debe destacarse que la ministra de educación de 1990 a 1998 -Cecilia Gallardo de Canohabía trabajado previamente con la FEPADE, y es de notar que también era miembro activo del núcleo duro del partido ARENA, estando estrecha- 
mente relacionada con los miembros más poderosos del partido, incluyendo al Presidente Cristiani. Más adelante, se convertiría en un entusiasta actor político, aspirante a la presidencia del país.

Antes de continuar con el desarrollo de los años noventa, es importante resaltar que el eventual triunfo del partido de derecha conocido como Alianza Republicana Nacionalista (ARENA) fue resultado-en parte-del fracaso del partido Democracia Cristiana bajo el mandato de José Napoleón Duarte. Inicialmente -después de su elección en 1984- Duarte fue inhabilitado por la mayoría de derecha en la Asamblea Legislativa, y por eso no pudo seguir adelante con la reforma agraria que había dado inicio con la Junta de Gobierno que estuvo en el poder antes de 1984. ${ }^{9}$ Después de 1985, aún con el control de la Asamblea Legislativa, Duarte y su partido no pudieron implementar sus políticas prioritarias y, es más, tenían opciones limitadas a causa de la combinación de diferentes factores y actores cómo las actividades de la milicia, el rol de la USAID y las preferencias políticas neoliberales y conservadoras de la élite salvadoreña. Ante la resistencia de estos actores, Duarte no podía negociar la paz ni promover programas de asistencia social, que era lo que él pretendía hacer. Duarte también falló en el intento de abrir la economía en la forma que muchos empresarios salvadoreños -y la administración Reagan- habrían querido. Por el contrario, implementó reformas económicas que desencadenaron una acelerada inflación y mayores impuestos sobre las importaciones ${ }^{10}$.

A raíz de esto -y con el apoyo de USAID- el candidato del partido de derecha,Alfredo Cristiani, ganó la presidencia en 1989. No es de sorprender que Cristiani y "al menos 17 hombres de negocio y personas relacio-

9 Ver:T. Montgomery, «Revolution in El Salvador: From civil strife to civil peace», 137-138, 187, para profundizar en la reforma agraria. En pocas palabras, esta reforma — que inició en 1980-, buscó nacionalizar grandes tierras (de más de 100 hectáreas) y transferir la propiedad de la tierra a aquellos que la rentaran. A inicios de 1985, el presupuesto para este programa fue eliminado por la Asamblea Nacional.

10 W. LeoGrande, «Our own backyard:The United States and Central America, 1977-1992». 
nadas con... [FUSADES] formaron parte del nuevo gobierno," incluyendo los ministros de planeación y finanzas y el director del Banco Central de Reserva $^{11}{ }^{12}$. Después de eso, ellos dieron seguimiento al paquete de reformas económicas que estaba siendo promovido por FUSADES y USAID. A pesar de que las reformas económicas y del sector público eran promovidas a menudo bajo la etiqueta inocua de "modernización," estaba claro que representaban la implementación de una perspectiva neoliberal en la política pública. Con ese fin, tal como indican los documentos del Banco Mundial, al mes siguiente a la toma del poder, Cristiani "puso en marcha un importante programa de estabilización y ajuste estructural" con el fin de "crear una economía guiada por un sector privado más liberalizado" ${ }^{13}$. El primer préstamo de ajuste estructural del Banco Mundial sería aprobado en 1991, seguido de un segundo en $1993^{14}$. Después de su elección, Cristiani también comenzó a convocar conversaciones de paz con el FMLN. Al menos en parte, esto se debió al hecho de que Cristiani y otros grandes empresarios se dieron cuenta de que sus inversiones en la banca y la industria podrían seguir sufriendo en un contexto del conflicto en curso. Los Acuerdos de Paz se firmaron finalmente en enero de 1992 con la ayuda de las Naciones Unidas.

11 A. Segovia, «Macroeconomic performance and policies since 1989» en Economic policy for building peace: The lessons of El Salvador, ed. J. K. Boyce (Boulder: Lynne Rienner, 1996), 55.

12 J. Eriksson, A. Kreimer and M. Arnold, «El Salvador: Post-conflict reconstruction: Country case evaluation» (Washington, D.C.: World Bank, 2000).

13 World Bank, «Report and recommendation of the President of the International Bank for Reconstruction and Development to the Executive Directors on a proposed structural adjustment loan in an amount equivalent to US\$75.0 million to the Republic of El Salvador» (Washington, D. C.: World Bank 1991a), 5.

14 A estos, les siguió un préstamo de «modernización del sector público» por parte del Banco Mundial en 1996. Para indagar más sobre el significado de estos préstamos en el contexto del total de ayuda durante los años 90, ver: H. Rosa, and M. Foley, «El Salvador. Good intentions: Pledges of aid for postconflict recovery» en Good intentions: Pledges of aid for postconflict recovery, ed. S. Forman and S. Patrick (USA: Lynne Rienner, 2000), 113-158. . 


\section{La emergencia de EDUCO: un proceso dinámico con intereses particulares}

Teniendo en cuenta todos los elementos contextuales expuestos previamente, ahora podemos centrar nuestra atención en el proceso específico en el cual emergió EDUCO. Una de las prioridades de la administración de Cristiani era mejorar el estado y manejo del sistema educativo. En esta área, el reto inmediato para la nueva Ministra de Educación, Cecilia Gallardo de Cano, quien asumió su puesto en 1990, era identificar una política aceptable para expandir el acceso a la educación. A nivel nacional, para 1990, al menos el 37\% de los niños con edades entre 7-14 años no estaban escolarizados y en las zonas conflictivas los servicios de educación provistos por el gobierno eran inexistentes ${ }^{15}$. Sin embargo, al momento de buscar opciones de reforma, Gallardo tenía que tomar en cuenta tres condiciones. Primero, la estrategia de reforma debía encajar dentro de la perspectiva de "modernización" que era el núcleo característico del gobierno de Cristiani, como ya se había mencionado. Para los servicios públicos -como la educación-, esto era sinónimo de reducir la burocracia e introducir un nuevo arreglo que garantizara eficiencia, efectividad y rendición de cuentas. Segundo, Gallardo debía evitar los sindicatos de maestros, pues no solo tenían una postura abiertamente contraria a la privatización, sino que además eran afines al FMLN. Tercero, el gobierno consideró necesario incorporar a las comunidades y escuelas asociadas con el FMLN dentro del sistema educativo oficial ${ }^{16}$. Esta tercera condición era particularmente esencial desde la perspectiva del gobierno, pues la Guerra Civil aún no había finalizado al momento que Gal-

15 Ministerio de Educación, «Servicios educativos a niños pobres salvadoreños de 0 a 14 años» (San Salvador: MINED, 1990).

16 Apuntamos que había aproximadamente mil maestros en las escuelas populares del FMLN. Cfr.V. Alvear Galindo, «La educación en Morazán, El Salvador, durante la guerra civil de 1981 a 1992: ¿parte de una estrategia de supervivencia?». Tesis Doctoral sin publicar (Berlin: Berlin Free University, 2002), 189-200. 
lardo estaba buscando opciones de reforma, y por tanto el gobierno aún estaba buscando formas de subyugar las regiones y escuelas controladas por el FMLN.

Fue en este contexto que -en 1990-, una consultora de UNESCO reconoció que el modelo de la gestión por parte de la comunidad podría tener éxito. Se le ocurrió esa idea a través del estudio de campo que hizo para el gobierno a mediados de año, cuando visitó todos los departamentos del país para recopilar información acerca del estado del sector educativo en aquel entonces. Como parte de esa investigación, la consultora observó de primera mano que muchas comunidades del país (pero sobre todo en las áreas conflictivas) ya estaban generando dinámicas de autogestión de la educación de sus niños. En muchas áreas, alguien de la comunidad ofrecía la educación primaria a los niños, recibiendo una compensación mínima (normalmente un pago nominal o la donación de comida) por parte de los padres. Además, en las áreas controladas por el FMLN, la escolarización provista también se fundamentaba en la tradición de la teología de la liberación y en las enseñanzas de Paolo Freire, en las que se enseña a los estudiantes a identificar-y movilizarse en contra de-las estructuras político-económicas que generan relaciones de opresión. En pocas palabras, este enfoque es conocido como "educación popular" 17 . Lo relevante en este caso es que el gobierno salvadoreño no solo estaba amenazado por la larga guerra de baja intensidad, sino también por el enfoque educativo del FMLN.

A finales de 1990, la sugerencia de la consultora para la gestión a nivel de la comunidad fue recibida con escepticismo. La Ministra no vioinicialmente- la idea como algo viable en términos políticos, porque estaba basada en el modelo de gestión utilizado en la mayoría de las comunidades afines al FMLN. Por su parte, el Banco Mundial dudaba que fuera posible implementar un modelo de descentralización donde los padres con bajos

17 J. Hammond, «Fighting to learn: Popular education and guerrilla war in El Salvador» (New Brunswick, NJ: Rutgers University Press, 1998) 
niveles educativos gestionaran sus escuelas locales. No obstante, después de la realización de un pequeño programa piloto-y gracias a la persistencia de la consultora de UNESCO-tanto la Ministra como el Banco Mundial empezaron a percibir las posibilidades que ofrecía ese modelo. Es decir, la Ministra se dio cuenta que esta propuesta (a) representaba un modelo innovador y (b) permitiría que el MINED incorporara a las comunidades del FMLN (y como tal eliminaría la educación popular). También, tanto la Ministra como el Banco Mundial vieron la posibilidad de disminuir el poder de los sindicatos, pues fue posible requerir que los maestros de este programa trabajaran bajo contratos anuales, de manera que esta modalidad de contrato afectaría solo a los maestros de este nuevo programa. Así, los sindicatos no se movilizaron con mucha fuerza para mostrar su oposición.

Por su parte, los representantes del Banco Mundial destacados en El Salvador también reconocieron que el modelo de la descentralización al nivel de la comunidad - si llegase a tener éxito-podría servir como una política a proponer en otros países, especialmente porque cuadraba con las tendencias internacionales de aquel entonces relacionadas con la participación y el pensamiento reformista neoliberal, como detallamos más adelan$\mathrm{te}^{18}$. Pero, antes de continuar, es necesario aclarar dos puntos para conocer las presiones y tendencias de esta época. Primero, durante los años ochenta e inicios de los noventa, el Banco Mundial estaba interesado en el desarrollo de la idea de la descentralización (Edwards, 2014b), una idea popular en el desarrollo internacional en aquel momento ${ }^{19}$. En aquella época, el Banco Mundial proponía modelos conceptuales que predecían el incremento de la eficiencia y la efectividad de la descentralización de los sistemas educativos ${ }^{20}$,

18 D.B. Edwards Jr. and D. DeMatthews, «Historical trends in educational decentralization in the United States and developing countries: A periodization and comparison in the postWWII context», Education Policy Analysis Archives 22 (2014), 1-36.

19 D. Conyers, «Decentralization: The latest fashion in development administration? " en Public Administration and Development, 3, (1983), 97-109

20 D. Winkler, «Decentralization in education: An economic perspective» (Washington, D.C.: The World Bank, 1989). 
pero no tenía evidencia empírica que lo apoyara. Es más, todavía no se le había ocurrido que sería posible descentralizar al nivel de la comunidad, más bien se centraba al nivel de los municipios. Segundo, entre finales de la década de los ochenta e inicios de los noventa, expertos en el ámbito del desarrollo internacional se interesaron mucho en la idea de que la "participación" fuera un componente central de una "buena" estrategia de desarrollo, especialmente cuando se trataba de una política educativa ${ }^{21}$. Esto se vio reflejado en marzo de 1990 en la declaración de la Conferencia Mundial de Educación para Todos (CMEPT), donde se aseveró que debía “...estimularse la concertación de acciones en el plano de la comunidad y en el nivel intermedio y nacional, ya que así se puede contribuir a armonizar actividades, utilizar los recursos más eficazmente y a obtener recursos financieros y humanos adicionales cuando sea necesario" ${ }^{22}$. Durante este período, las organizaciones internacionales también promovieron el concepto de participación. En particular, la USAID planteó la cuestión como una vía para la promoción de la democracia y la efectividad de las instituciones públicas ${ }^{23}$.

Por las razones anteriores, la Ministra y el Banco Mundial decidieron apoyar el modelo. Era importante que el Banco Mundial creyera en el modelo porque era esta institución quien financiaría la reforma administrativa del MINED. A mediados de 1991, estos dos actores firmaron un primer préstamo de 10.3 millones de dólares para el sector educativo para llevar a cabo el modelo de la gestión de las escuelas locales por parte de padres de familia. Para ese entonces, ese modelo se llamaba "Educación con Participación de la Comunidad" (EDUCO). Con el paso de los años, este

21 D. Edwards, «El concepto del Banco Mundial de la participación en el desarrollo y la gobernanza de la educación: Un análisis de su acercamiento y resultados» en Revista Latinoamericana de Estudios Educativos (2014), 13-46.

22 Marco de Acción CMEPT, 1990, 12, citado en Community initiatives in education: Goals, dimensions and linkages with governments, M. Bray, compare 33 (2003), 31-45.

23 A. Montero and D. Samuels, «Decentralization and Democracy in Latin America» (Notre Dame: University of Notre Dame Press, 2004). 
programa recibió mucho apoyo del Banco Mundial y el Banco Interamericano de Desarrollo. Estas dos instituciones proveyeron un total de 69.3 millones de dólares en préstamos para la reforma del sistema educativo y la ampliación y mejora del programa EDUCO entre 1991 y 2006. Además, es relevante indicar que la decisión de llevar a cabo esta reforma se tomó antes de la firma de los Acuerdos de Paz de enero de 1992. Una implicación clave es que la estrategia de reforma de la administración educativa fue elegida antes de que terminara la guerra y, concomitantemente, antes de que el proceso oficial de investigación y consulta posconflicto siquiera hubiera empezado ${ }^{24}$.

Con los años y con la asistencia técnica del Banco Mundial y UNESCO, las características del programa fueron definidas. No es de sorprender que, tanto la teoría que guio el desarrollo del programa, como los arreglos prácticos que le dieron vida, fueran orientados por una perspectiva neoliberal del manejo de la educación. Para ser específicos, el programa planteaba que un grupo de cinco padres de familia de cada comunidad fueran elegidos -como voluntarios- para formar una Asociación Comunal para la Educación (ACE), entidad a la que se le otorgaba estatus legal y era la encargada de contratar y pagar-con fondos transferidos por el MINED a las ACEs a través de una cuenta bancaria- a los maestros que trabajaran en las escuelas de su comunidad $^{25}$. Las ACEs también fueron concebidas como un mecanismo de rendición de cuentas. Dado que se basaban en la comunidad y tenían la

24 D.B. Edwards Jr., J.Victoria and P. Martin, «Corrientes internacionales, desarrollos estructurales, preferencias nacionales y la implementación de políticas educativas: Hallazgos en El Salvador durante el periodo 1990-2005».

25 Mientras el programa EDUCO fue pensado inicialmente como una estrategia para proveer educación a nivel pre escolar y de primero a tercer grado, se fue expandiendo y, en 1994, cubría hasta el sexto grado, y de ahí nuevamente, en 1997, cubría hasta noveno grado Cfr. Meza, Guzmán, \& Varela, «EDUCO:A community-managed education program in rural areas of El Salvador». Paper presented at Scaling Up Poverty Reduction:A Global Learning Process and Conference (Shanghai, May 25-27, 2004). Después de 2005, incluso algunas escuelas de bachillerato se volvieron escuelas EDUCO. Cfr. J. Gilles, L. Crouch, \& A. Flórez, «Revisión estratégica del programa EDUCO» (USAID, 2010). Disponible en: http://www.equip123. net/docs/E2_REVISION_DEL_PROGRAMA_EDUCO.Pdf 
habilidad de monitorear a los maestros, la teoría del programa sugería que las ACEs podían reducir el absentismo de estos últimos; además, esta reducción se debería traducir en un incremento del esfuerzo de los maestros en las aulas como consecuencia del método de contratación -a través de contratos por un año-. Otro aspecto era que, con los fondos provistos por el MINED, cada ACE tenía la responsabilidad de comprar los materiales didácticos necesarios. ${ }^{26} \mathrm{~A}$ través de estas acciones se buscaba reducir el gasto excesivo (y en consecuencia incrementar la eficiencia de la provisión) y además mejorar los desempeños de los estudiantes (y por tanto incrementar la efectividad). Dada esta situación, los padres en comunidades rurales en desventaja, eran requeridos para asumir responsabilidades que, tradicionalmente, conciernen al Estado, pero sin compensación. Además, se esperaba que los miembros de la comunidad dedicaran tiempo, trabajo y materiales para la construcción o para el mantenimiento de su escuela local, particularmente al inicio del programa -y esto era aunado a los costos básicos en que los padres incurrían para mantener a sus hijos matriculados en la escuela-. El MINED, por su parte, era responsable de: facilitar la creación de las ACEs; capacitar a los miembros de las ACEs en procedimientos de administración y rendición de cuentas; definir los criterios mínimos de selección de maestros para las ACEs;

26 Dada esta situación, los padres en comunidades rurales en desventaja eran requeridos para asumir responsabilidades, que tradicionalmente conciernen al Estado, y sin compensación. Además, se esperaba que los miembros de la comunidad dedicaran tiempo, trabajo y materiales para la construcción o para el mantenimiento de su escuela local, particularmente al inicio del programa - y esto era aunado a los costos básicos en que los padres incurrían para mantener a sus hijos matriculados en la escuela-. 
diseñar y proveer la currícula; y en general coordinar, supervisar y monitorear el programa en la medida que se iba expandiendo 2728 .

Así, desde finales de 1991, el MINED estuvo comprometido con la expansión e implementación del programa EDUCO, que pronto se convirtió en el único programa a través del cual se lograría que el acceso a la educación aumentara. En 1993, el programa estaba operando en los 14 departamentos del país, y en 1995, el programa había sido institucionalizado y la oficina de EDUCO había sido incorporada dentro de la estructura administrativa de MINED $^{30}$. En términos numéricos, el programa inició como propuesta piloto con seis escuelas en enero de 1991, pasando a 114 escuelas al finalizar ese mismo año. Para 2004, el programa contaba con

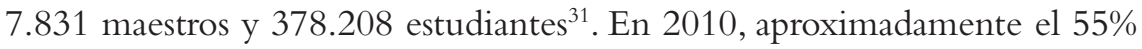
de las escuelas públicas rurales -lo que equivale a dos tercios de todas las escuelas en El Salvador- operarían bajo el programa EDUCO ${ }^{32}$. La continua popularidad y expansión del programa se debía, entre otras razones, al éxito percibido y al hecho que el partido ARENA—con su preferencia hacia la reforma neoliberal—retuvo la presidencia hasta $2009^{33}$.

27 F. Reimers, «The role of the community in expanding educational opportunities: The EDUCO schools in El Salvador» en Education and development:Tradition and innovation. Equity and excellence in education for development.Vol. 2, ed. J. Lynch, C. Modgil, \& S. Modgil (London: Cassell, 1997), 146-162.

28 World Bank, «El Salvador: Community education strategy: Decentralized school management» (Washington, D.C.: The World Bank, 1994).

29 Para más detalles respecto a los aspectos técnicos del programa EDUCO, ver: J. Gilles, L. Crouch, y A. Flórez, «Revisión estratégica del programa EDUCO», 2010.

30 B. Edwards, «The trajectory of global education policy: Community-Based Management in El Salvador and the global reform agenda» (New York: Palgrave MacMillan, próximamente).

31 Helga Cuéllar-Marchelli, «Decentralization and privatization of education in El Salvador: Assessing the experience» International Journal of Educational Development 23 (2003a), 45-166.

32 J. Gillies, L. Crouch y A. Flórez, «Revisión estratégica del programa EDUCO» (USAID, 2010). Disponible en: http://www.equip123.net/docs/E2_REVISION_DEL_PROGRAMA_EDUCO.Pdf

33 Para más información acerca del programa EDUCO en el periodo posterior a 2009, ver:

B. Edwards, «The trajectory of global education policy: Community-Based Management in

El Salvador and the global reform agenda», próximamente. 
Un elemento evidente que surge de la historia de EDUCO es que este programa se desarrolló de forma completamente independiente del proceso oficial de reforma educativa que tuvo lugar en el periodo de posguerra. En este sentido, como más adelante será abordado en la sección de discusión del artículo, mientras EDUCO fue incluido en el Plan Decenal para la reforma educativa, que fue publicado en 1995, EDUCO no fue el resultado del proceso público de diseño de las políticas educativas que tuvo lugar entre 1993 y 1995. Al contrario, tal y como se ha mostrado anteriormente, EDUCO fue el resultado de un conjunto de dinámicas particulares dadas entre los representantes del MINED, UNESCO y el Banco Mundial. Por supuesto, es preocupante que estas dinámicas tuvieran lugar a "puerta cerrada" y no fueran sujetas al debate y escrutinio público. Como se ha presentado en esta sección, el siguiente apartado también saca a la luz nuevos elementos de EDUCO, a pesar de que se centra más concretamente en el funcionamiento de EDUCO en términos prácticos.

\section{Una revisión crítica de los resultados de EDUCO y su funcionamiento en el ámbito comunitario}

\section{Resultados generales y consideraciones a nivel de sistema}

Antes de volver a la discusión sobre los estudios que analizan el funcionamiento de EDUCO a nivel comunitario, dos aspectos sobre la evidencia del programa deben ser subrayados. Primero, es necesario destacar que existen no menos que nueve estudios cuantitativos sobre EDUCO, de los cuales siete fueron llevados a cabo por el Banco Mundial. Si bien los estudios del Banco Mundial han jugado un rol destacado en la promoción global de EDUCO -en los cuales se destacaron efectos positivos en términos de resultados y retención de los estudiantes- existen otros estudios que han desarrollado revisiones críticas de los métodos y las interpretaciones, que muestran 
que los hallazgos del Banco Mundial no pueden ser concluyentes ${ }^{34}{ }^{35}$. Quizás más rotundo sea el hecho de que en los modelos donde las limitaciones de los estudios del Banco Mundial han sido superadas, se ha demostrado que EDUCO ha tenido en realidad efectos negativos en los logros de los estudiantes $^{36}$. Este es un punto clave, ya que EDUCO ha sido generalmente presentado como un programa con efectos positivos para los logros de los estudiantes a pesar de que este no sea el caso.

Por otro lado, existen estudios ${ }^{37}$ que analizan los problemas de EDUCO desde una perspectiva de sistema, examinando las dimensiones de acceso, equidad, eficiencia y cohesión social. Más allá de los efectos de EDUCO, se plantean serias dudas sobre sus beneficios en un sentido amplio. Para sintetizar, a pesar de que se atribuyen grandes beneficios a EDUCO en términos de acceso, particularmente en áreas rurales donde el programa fue aplicado (debido a que estas fueron las zonas de más necesidad después de la destrucción que implicó la guerra civil), no hay manera de saber si otro enfoque $\mathrm{u}$ otra reforma hubiera generado las mismas mejoras. Respecto la equidad, EDUCO es problemático debido a la carga de trabajo que pudo suponer, teniendo en cuenta que la contribución laboral por parte de las familias fue equivalente al trabajo de 805 trabajadores a jornada completa (una

34 B. Edwards, «The trajectory of global education policy: Community-Based Management in El Salvador and the global reform agenda», próximamente.

35 D. B. Edwards Jr. y C. Loucel, «El programa EDUCO, las evaluaciones de impacto y la economía política de la reforma educativa global, Archivos Analíticos de Políticas Educativas», 24 (49), 1-50, 2016. Disponible en: https://www.researchgate.net/profile/D_Brent_Edwards_ Jr/publication/307605550_El_Programa_EDUCO_las_Evaluaciones_de_Impacto_y_la_ Economia_Politica_de_la_Reforma_Educativa_Global/links/57ccf70e08ae3ac722b473b7.pdf 36 Helga Cuéllar-Marchelli, «The cost-effectiveness of EDUCO and traditional public school in rural El Salvador». Unpublished dissertation (New York: Teachers College, Columbia University, 2003b).

Para una discusión que contraste el estudio de Cuéllar-Marchelli (2003b) con los estudios del Banco Mundial, ver: B. Edwards, "The trajectory of global education policy: Community-Based Management in El Salvador and the global reform agenda", próximamente.

37 Helga Cuéllar-Marchelli, «Decentralization and privatization of education in El Salvador: Assessing the experience», 2003a. 
cantidad que equivale al 28\% del trabajo hecho por personal del MINED). Por supuesto, el trabajo de las familias se añade a otras preocupaciones en términos de equidad. El hecho de que EDUCO funcionó en comunidades marginalizadas y económicamente desfavorecidas es evidente, por ejemplo, teniendo en cuenta que el 61\% no tenían electricidad y el 74\% no tenían agua corriente (en comparación con el 15\% y el 48\% respectivamente, en las escuelas públicas tradicionales). La eficiencia tiene que ver con los efectos de EDUCO en relación a sus costes. A pesar de que no hay una respuesta clara en este campo, ya que las evaluaciones no han examinado los costes, se ha demostrado que en términos de gastos, el programa fue más caro por el gobierno (en contra de la retórica alrededor de EDUCO), porqué muy pocas comunidades pagaron todas las tasas escolares ${ }^{38}$. Respecto la última dimensión — la cohesión social—, la investigación de Cuéllar-Marchelli no solo muestra que la participación varía entre comunidades sino también concluye que "mientras EDUCO pretende una mayor cohesión social, su éxito depende ampliamente de la capacidad de cohesión social previamente existente" ${ }^{39}$. Este es un punto importante, tal y como se clarificará en la discusión que sigue. En general, el propósito de los comentarios anteriores es subrayar brevemente las limitaciones de EDUCO a nivel de sistema antes de profundizar a continuación con los aspectos del programa a nivel comunitario.

38 Helga Cuéllar-Marchelli, "The cost-effectiveness of EDUCO and traditional public school in rural El Salvador», 2003b.

39 Helga Cuéllar-Marchelli, «Decentralization and privatization of education in El Salvador: Assessing the experience», 2003a. 


\section{Una aproximación al nivel comunitario}

La explicación presentada más arriba nos ayuda a contextualizar los hallazgos de un conjunto de estudios que han examinado EDUCO con más profundidad. Al revisar estos estudios, el propósito es destacar algunos aspectos de EDUCO que habían recibido menos atención, como ahora elementos relacionados con los mecanismos y los procesos que dieron vida a EDU$\mathrm{CO}$ (ya que como se clarifica en las conclusiones, el programa no sigue activo; el Presidente que asumió el poder en 2009 empezó el proceso de cancelación el programa EDUCO). Con este propósito nos basamos en seis estudios cualitativos, la mayoría de los cuales han pasado desapercibidos por académicos y responsables políticos, tanto dentro de El Salvador como en la literatura internacional sobre EDUCO. Nos centramos primeramente en el que representa un estudio particularmente amplio de EDUCO y sus mecanismos a nivel comunitario. Este estudio fue llevado a cabo por Ayala ${ }^{40} \mathrm{e}$ investigó el funcionamiento de EDUCO en 23 comunidades en 10 de los 14 departamentos del país. Dicha investigación se complementa con otros cinco estudios de caso, que se centran tanto en una mirada más concreta sobre el programa EDUCO, por ejemplo en una o pocas comunidades ${ }^{41} 4243$ así como en análisis más amplios a partir de varios métodos, como entrevistas y grupos de discusión con miembros que trabajaron con EDUCO en

40 R. Ayala, «Evaluación del programa de Educación con Participación de la Comunidad-EDUCO» (San Salvador: MINED, 2005).

41 A. Ávila de Parada y Landaverde de Romero, M., «La gestión educativa y el desempeño de centros escolares de la modalidad Educación con Participación de la Comunidad (EDUCO) en El Salvador». Tesis Doctoral sin publicar (San Salvador: Universidad Centroamericana José Simeón Cañas, 2007).

42 C. Desmond, «EDUCO schools in El Salvador: A democratic tree in a globalized forest?» International Education, 38 (2) (2009), 7-28.

43 M. Srygley, «Education in rural El Salvador: A case study on value, quality, and accountability». Unpublished thesis (Maryland: University of Maryland, College Park, 2013). 
varios niveles, incluyendo el comunitario $444^{45} 46$. Se argumenta que tomados en su conjunto, estos estudios nos permiten una mirada amplia sobre el funcionamiento de EDUCO. Siguiendo Alaya ${ }^{47}$ los hallazgos presentados aquí son agrupados de acuerdo con (a) la estructura institucional de EDUCO, (b) la participación comunitaria, (c) la gestión de las ACE, (d) el trato a los maestros y (e) aspectos pedagógicos.

\section{La estructura institucional de EDUCO}

Generalmente, el programa EDUCO ha sido caracterizado como un proceso de reforma administrativa que, irónicamente a lo largo del tiempo, ha aumentado la burocracia del MINED. Este aspecto es particularmente relevante en relación al pago de los maestros ya que estos eran empleados por las ACEs pero el gobierno se ocupaba del pago de las nóminas, llevando al desarrollo de un sistema "enrevesado" en relación a la emisión de cheques al profesorado ${ }^{48}$. Además, a medida que se extendió el programa, la oficina de EDUCO quedó pequeña, con capacidad limitada y con acceso a pocos recursos para cubrir el programa. Esto se puso de relieve por el hecho que el personal de apoyo estaba al cargo de hasta 100 ACEs, muchas de las

44 J. Gillies, L. Crouch y A. Flórez, «Revisión estratégica del programa EDUCO», 2010. 45 World Bank, «Strengthening accountability in social service delivery in Central America: The EDUCO school-based management model» (Washington, D.C.: World Bank, 2009). 46 Not discussed here is H. Lindo Fuentes, "Comunidad, participación y escuelas: EDUCO en El Salvado») (Washington, D.C.: World Bank, 1998) who studied 36 EDUCO communities. The reason for this is that this study was produced for the World Bank and is seen to suffer from a conflict of interest, since the World Bank was also funding the EDUCO program. The difference between Lindo Fuentes and World Bank, Strengthening accountability in social service delivery in Central America: The EDUCO school-based management model (Washington, D.C.: World Bank, 2009) is that the latter was produced for an internal audience, that is, it was not meant for public dissemination, and thus the content is judged to be less encumbered by a preoccupation with how the commentary contained therein would affect perceptions of the EDUCO program.

47 R. Ayala, «Evaluación del programa de Educación con Participación de la Comunidad-EDUCO», 2005.

48 J. Gillies, L. Crouch y A. Flórez, «Revisión estratégica del programa EDUCO», 2010. 
cuales eran de dificil acceso geográfico, con el resultado de que muchas ACEs no veían a su personal de apoyo más de una vez al año. En los casos que el personal de apoyo iba a las escuelas, lo hacían sin aviso previo, con la implicación que las ACEs no se podían reunir con los técnicos, que simplemente resumían y signaban los documentos necesarios. Además, no había comunicación con las ACEs sobre los resultados de la visita, o los datos de los técnicos en relación al rendimiento de las ACE. La falta de apoyo estuvo acompañada por la manca de formación del personal del programa en todos los niveles, que únicamente implicó una mayor desconexión entre los elementos de gestión y los aspectos pedagógicos del programa ${ }^{49}{ }^{50}$. En relación a este punto, también se ha destacado que muchas escuelas EDUCO no tenían director, que muchos maestros actuaban como tal a pesar de no estar designados, y que las escuelas con directores tenían pocos incentivos para el director en el apoyo a los docentes, debido al conflicto de autoridad que establecía la figura de las ACEs. ${ }^{51}$

\section{Participación comunitaria}

La participación comunitaria tendió a estar restringida a aquellas familias que formaban parte de las ACEs, excepto cuando los maestros convocaban reuniones de nivel, a pesar de que esta tendencia dependía de la historia de las comunidades y de su capital social pre-existente ${ }^{52}$. Sorprendentemente, otros estudios también demuestran que la mayoría de los miembros de la

49 A. Ávila de Parada y Landaverde de Romero, M., «La gestión educativa y el desempeño de centros escolares de la modalidad Educación con Participación de la Comunidad (EDUCO) en El Salvador», 2007.

50 R. Ayala, «Evaluación del programa de Educación con Participación de la Comunidad-EDUCO», 2005.

51 J. Gillies, L. Crouch y A. Flórez, «Revisión estratégica del programa EDUCO», 2010, $25-$ 26.

52 A. Ávila de Parada y Landaverde de Romero, M., «La gestión educativa y el desempeño de centros escolares de la modalidad Educación con Participación de la Comunidad (EDUCO)", 2007, 93-94. 
comunidad no conocían que era EDUCO ${ }^{53}{ }^{54}$. Por su parte, los miembros de las ACEs sabían que, de acuerdo con el programa, debían dinamizar la participación comunitaria, pero no tenían claro cómo desarrollar este rol ya que no recibieron formación para ello y no estaban completamente seguros de lo que significaba a la práctica dicha participación. Como resultado, se centraron en otras tareas como la construcción de las escuelas, el aumento de las donaciones, la involucración de los padres en tareas de cocina, limpieza o reparación, la recaudación de fondos de la AND así como en acompañar a los directores a las visitas a las agencias gubernamentales en relación con asuntos escolares ${ }^{55}{ }^{56}$. A pesar de que el gobierno también esperaba que los maestros pudieran ofrecer clases de alfabetización a las familias, estas se desarrollaron de forma inconsistente, fueron valoradas como de baja calidad y solo tenían lugar cuando a los maestros les iba bien (durante el día y entre semana, de modo que tan solo las madres, pero no los padres podían participar regularmente) $)^{57}$.

53 R. Ayala, «Evaluación del programa de Educación con Participación de la Comunidad-EDUCO», 2005.

54 M. Srygley, «Education in rural El Salvador: A case study on value, quality, and accountability", 2013.

55 R. Ayala, «Evaluación del programa de Educación con Participación de la Comunidad-EDUCO», 2005, 11.

56 J. Gillies, L. Crouch y A. Flórez, «Revisión estratégica del programa EDUCO», 2010, 24. 57 R. Ayala, «Evaluación del programa de Educación con Participación de la Comunidad-EDUCO», 2005, 11. 


\section{La gestión de las ACEs}

Los estudios describen que los miembros de las ACEs tenían poca experiencia y bajos niveles de alfabetización ${ }^{58}{ }^{59}$. Las decisiones que tomaban las ACEs habitualmente tan solo reflejaban las preferencias de dos o tres de los miembros más activos, a pesar de que dichas decisiones también eran a menudo influenciadas por los maestros, preguntados por asistencia u orientación a petición de los miembros de las ACEs ${ }^{60}$. Si bien la comunicación entre los miembros de las ACEs era infrecuente, casual y a menudo dirigida por el profesorado, las ACEs llevaron a cabo una valiosa tarea en relación al uso de los fondos de las escuelas, con trabajos de mantenimiento, reparación y construcción, o con tareas vinculadas a la adquisición de recursos (ordenadores, televisores, fotocopiadoras, neveras, etc.). También signaban los cheques de los maestros, hacían ingresos y pagas, y a veces monitorizaban la asistencia y el trabajo del profesorado ${ }^{61}$.

No obstante, se mostró que la mayoría de los miembros de las ACEs no estaban familiarizados con documentos básicos como acuerdos o contratos y parecían signar únicamente los documentos necesarios para mantener el funcionamiento de la escuela ${ }^{62}$. Quizás debido al bajo nivel educativo de las familias, las ACEs permitieron a menudo que los profesores, directores

58 A. Ávila de Parada y Landaverde de Romero, M., «La gestión educativa y el desempeño de centros escolares de la modalidad Educación con Participación de la Comunidad (EDUCO)", 2007.

59 C. Desmond, «EDUCO schools in El Salvador:A democratic tree in a globalized forest?», 2009.

60 R. Ayala, «Evaluación del programa de Educación con Participación de la Comunidad-EDUCO", 2005.

61 R. Ayala, «Evaluación del programa de Educación con Participación de la Comunidad-EDUCO», 2005.

62 R. Ayala, «Evaluación del programa de Educación con Participación de la Comunidad-EDUCO», 2005. 
y los técnicos del MINED tomaran decisiones por su cuenta ${ }^{63}$. Estas decisiones incluían la contratación de los maestros por parte del director de la escuela, por otro profesor o por algún miembro de la oficina del MINED, que podía llegar a enviar profesores preseleccionados a las ACEs para contratarlos $^{64}$. En los 2000, fuera del reconocimiento de las responsabilidades administrativas de las familias, el MINED creo el puesto de "agente tramitadora" que debía ayudar con la gestión de las nóminas y la redacción de reportes y formularios relacionados, por ejemplo, con el pago de los impuestos de la renda al Ministerio de Hacienda o las contribuciones a la seguridad social y a las pensiones ${ }^{65}$.

Al final, las ACEs fueron vistas como necesarias pero no por su capacidad de rendir cuentas sobre el profesorado, sino porque se asumió que "si no había ACE no había escuela" ${ }^{66}$. De este modo, las ACEs se convirtieron en entidades mecánicas que no contribuían a la rendición de cuentas ni funcionaban en otros modos esperados. En efecto, contrariamente a la teoría y la retórica de EDUCO, se apunta: “el peso de la 'gestión' deja poco espacio para los aspectos curriculares y pedagógicos. Existe la necesidad de recuperar un enfoque más integral, que ponga los aspectos administrativos y financieros en función de la enseñanza y el aprendizaje y no a la inversa" ${ }^{\text {"67 }}$. Lo que destaca en este punto es que esta es la misma crítica que a menudo se lanza contra las escuelas públicas. En lugar de operar como mecanismos

63 A. Ávila de Parada y Landaverde de Romero, «La gestión educativa y el desempeño de centros escolares de la modalidad Educación con Participación de la Comunidad (EDUCO)", 2007. R. Ayala, «Evaluación del programa de Educación con Participación de la Comunidad-EDUCO», 2005. J. Gillies, L. Crouch y A. Florez, «Revisión estratégica del programa EDUCO», 2010.

64 R. Ayala, "Evaluación del programa de Educación con Participación de la Comunidad-EDUCO», 2005.

65 J. Gillies, L. Crouch y A. Florez, «Revisión estratégica del programa EDUCO», 2010.

66 R. Ayala, «Evaluación del programa de Educación con Participación de la Comunidad-EDUCO», 2005, 14.

67 A. Ávila de Parada y Landaverde de Romero, M., «La gestión educativa y el desempeño de centros escolares de la modalidad Educación con Participación de la Comunidad (EDUCO)», 2007, 120. 
independientes, las ACEs fallaron en sus funciones tal y como fueron diseñadas, en parte porqué el MINED no ofreció formación ni asistencia técnica, y en los casos que esta asistencia se ofrecía, tendía a ser para desempeñar tareas a cargo de las ACEs en lugar de trabajar para incrementar su capacidad ${ }^{68}$.

\section{El trato a los maestros}

De todos los implicados en EDUCO, los docentes fueron los que tuvieron una posición más desaventajada. Por ejemplo, un estudio mostró que "las familias ejercen su autoridad usando amenazas de recortes en los sueldos o directamente de despido, mientras que el profesorado no tiene derecho a recurrir. Además, si se pierde el puesto los profesores son excluidos del plan de pensiones" ${ }^{\prime 9}$. También en relación a la contratación, Desmond recogió malas prácticas por parte de las ACEs, tanto en términos de nepotismo como en formas de corrupción ${ }^{70}$. Aunque tales casos parecen ser pocos y distantes entre sí, es difícil juzgar con certeza su frecuencia y alcance.

Hay otros aspectos que también deben ser subrayados de modo particular, ya que son cuestiones normalmente omitidas o subestimadas en relación al funcionamiento de EDUCO. Primero, dadas las dinámicas recogidas en las secciones previas, los profesores tendían a ver las ACEs como necesarias únicamente en la medida que eran responsables de su contratación, autorizaban el pago de su salario y les daban apoyo en algunas actividades ${ }^{71}$. En segundo lugar, los profesores no tenían acceso a préstamos bancarios o

68 R. Ayala, «Evaluación del programa de Educación con Participación de la Comunidad-EDUCO», 2005.

69 World Bank. «Strengthening accountability in social service delivery in Central America: The EDUCO school-based management model», 2009.

70 C. Desmond, «EDUCO schools in El Salvador: A democratic tree in a globalized forest? ", 2009, 20.

71 R. Ayala, «Evaluación del programa de Educación con Participación de la Comunidad-EDUCO», 2005. 
hipotecas debido a la naturaleza anual de sus contratos de trabajo ${ }^{72}$. Tercero, los docentes no recibieron formación sobre el programa EDUCO ni tampoco sobre cómo promover la participación comunitaria ${ }^{73}$, a pesar de que hacia el 2005 los docentes de EDUCO fueron incorporados al sistema de desarrollo profesional docente ${ }^{74}$ (durante los años 1991 - 1999 hubo una o dos formaciones de 40 horas cada año para los maestros de EDUCO, y ninguna durante los años 2000 - 2004). En cuarto lugar, el pago de los salarios de los maestros se hacía a menudo con retraso, a veces debido a los ritmos del MINED y otras veces porqué algunas "ACEs pagaban tarde para afirmar su poder sobre las finanzas de la escuela"75. Quinto y último, no había mecanismos de queja para las familias o los docentes de las escuelas EDUCO, en tanto que las ACEs y las escuelas eran vistas como entidades legales propias más allá del MINED ${ }^{76}$.

Saliendo del nivel comunitario por un momento, se pueden hacer algunos comentarios adicionales sobre las circunstancias, en gran parte ignoradas, en las cuales trabajaban los docentes de EDUCO. Inicialmente, de acuerdo con los documentos del Banco Mundial, los docentes de EDUCO al nivel de preescolar debían ser pagados con 160 dólares al mes ${ }^{77}$. Aun así, a partir del 1995 empezaron a recibir incentivos (40 dólares al mes) por trabajar en áreas rurales ${ }^{78}$. Con estos incentivos, los profesores de EDUCO cobraban de media un 7\% más que los profesores en las escuelas tradiciona-

72 R. Ayala, «Evaluación del programa de Educación con Participación de la Comunidad-EDUCO", 2005.

73 R. Ayala, «Evaluación del programa de Educación con Participación de la Comunidad-EDUCO», 2005.

74 J. Gillies, L. Crouch y A. Flórez, «Revisión estratégica del programa EDUCO», 2010.

75 C. Desmond, «EDUCO schools in El Salvador: A democratic tree in a globalized forest?», 2009, 19.

76 J. Gillies, L. Crouch y A. Flórez, «Revisión estratégica del programa EDUCO», 2010, 29. 77 World Bank, «Staff appraisal report. El Salvador: Social Sector Rehabilitation Project» (Washington, D.C.: World Bank, 1991b).

78 J. Gillies, L. Crouch y A. Flórez, «Revisión estratégica del programa EDUCO», 2010. 
les ${ }^{79}$. A pesar de esto, se tiene que subrayar que los docentes de EDUCO no tenían la posibilidad de recibir incrementos salariales por antigüedad, como los otros profesores, lo cual fue una desventaja relevante ya que los maestros de las escuelas tradicionales podían llegar a cobrar con el tiempo el $50 \%$ más del salario inicial, debido a los aumentos salariales automáticos que se reciben cada cinco años ${ }^{80}$.

Además, los profesores de EDUCO no podían optar a otros beneficios dados por el gobierno en las escuelas tradicionales, como el plan oficial de retiro, un seguro de vida o el acceso al sistema de salud para los docentes ${ }^{81}$, a pesar de que sí que podían acceder a los servicios sanitarios a través del Instituto de la Seguridad Social de El Salvador ${ }^{82}$. En el 2007, los maestros de EDUCO empezaron a cobrar de acuerdo con las escalas salariales del MINED, con el reconocimiento de sus años de trabajo reflejados en los nuevos salarios, pero aun sin tener acceso al sistema de seguridad laboral ofrecido a los docentes miembros del Sistema de Carrera docente del MINED ${ }^{83}$. Como parte del cambio hacia la escala salarial de EDUCO, "se estructuró el escalafón de los docentes EDUCO para que pudieran acumular tiempo de servicio y acceso a ascensos de categoría que les permitieran tener aumentos salariales cada cinco años" ${ }^{" 4}$.

En conjunto, los detalles presentados en esta sección ponen de relieve el hecho que, más allá de las difíciles condiciones laborales en la escuela y en el nivel comunitario, los profesores de EDUCO fueron severamente desaventajados en relación con los docentes de las escuelas públicas tradicio-

79 J. Gillies, L. Crouch y A. Flórez, «Revisión estratégica del programa EDUCO», 2010, 64. 80 J.C. Rodríguez, «Incentivos a Escuelas y Maestros: La experiencia del «Plan de Estímulos a la labor educativa Institucional en El Salvador». (Chile: Universidad de Chile, Facultad de Ciencias Físicas y Matemáticas, Departamento de Ingeniería Industrial, 2003).

81 Helga Cuéllar-Marchelli, "The cost-effectiveness of EDUCO and traditional public school in rural El Salvador», 2003b.

82 J. Gillies, L. Crouch y A. Flórez, «Revisión estratégica del programa EDUCO», 2010, 27.

83 C. Ramírez, «EDUCO inició este mes su ingreso al escalafón» La Prensa Gráfica. Marzo 24, 2007.

84 J. Gillies, L. Crouch y A. Flórez, «Revisión estratégica del programa EDUCO», 2010, 71. 
nales, un hecho que pone en duda la asunción que suponía que el modelo EDUCO haría trabajar más duro a los profesores que a su contraparte en las escuelas públicas.

\section{Aspectos pedagógicos}

A pesar de las asunciones sobre la capacidad de EDUCO para generar relaciones de rendición de cuentas que podrían hacer trabajar más duro a los docentes y mejorar la enseñanza, no se han encontrado estudios que hayan examinado las practicas docentes reales entre los maestros de EDUCO. En cambio, muchas investigaciones mencionan la manca de recursos en las escuelas del programa, incluyendo libros, el currículo oficial, los materiales didácticos y material recreativo ${ }^{85}$, aunque esta también sea una problemática en las escuelas públicas tradicionales ${ }^{86}{ }^{87}$. Por otro lado, la calidad docente se debilitó aún más por el hecho de que las visitas de expertos pedagógicos del MINED fueron infrecuentes (en un rango de 1 a 5 visitas al año) ${ }^{88}$, además

85 A. Ávila de Parada y Landaverde de Romero, M., «La gestión educativa y el desempeño de centros escolares de la modalidad Educación con Participación de la Comunidad (EDUCO)", 2007. R. Ayala, «Evaluación del programa de Educación con Participación de la Comunidad-EDUCO», 2005. C.Desmond, "EDUCO schools in El Salvador: A democratic tree in a globalized forest?», 2009.

86 Helga Cuéllar-Marchelli, «The cost-effectiveness of EDUCO and traditional public school in rural El Salvador», 2003b.

87 Para saber más sobre el sistema educativo del El Salvador ver: D. B. Edwards Jr., Martin, P., and Flores, I., «Education in El Salvador: Past, present, and prospects» n.p. in Education in México, Central America and the Latin Caribbean, Continuum, ed. C. M. Posner, Chris Martin,Yvonne Martin (próximamente-a) y D. B. Edwards Jr., Martin, P., and Flores, I., «Teacher education in El Salvador: Politics, policy, pitfalls» in International handbook of teacher education, ed. C. Wolhuter (Athens: Atrapos, próximamente-b). Por algunos elementos comparativos considerar que el 81\% públicas tradicionales tienen pupitres frente al 78\% de las escuelas EDUCO; $41 \%$ frente al $42 \%$ tienen libros de matemáticas, y el 38\% respecto al 32\% tienen libros de lengua. Cfr. Helga Cuéllar-Marchelli, «The cost-effectiveness of EDUCO and traditional public school in rural El Salvador», 2003b.

88 A. Ávila de Parada y Landaverde de Romero, M., «La gestión educativa y el desempeño de centros escolares de la modalidad Educación con Participación de la Comunidad (EDUCO)», 2007. R. Ayala, «Evaluación del programa de Educación con Participación de la Comunidad-EDUCO", 2005, 30. 
de problemas de masificación en las aulas ${ }^{89}$. En relación a esta cuestión, Cuéllar-Marchelli reportó (en el año 1998) ratios de 60 y 50 estudiantes por profesor para las escuelas EDUCO y las escuelas públicas tradicionales, respectivamente ${ }^{90}$. Un último asunto que mencionar aquí, es que el 39\% de las escuelas EDUCO tenían múltiples cursos en la misma clase (hasta 3) pero sin los recursos adecuados para responder a los retos asociados ${ }^{91}$. A la luz de los obstáculos detallados en esta y en las secciones previas de este artículo, no es sorprendente - y en efecto debería ser lo esperado - que el modelo de EDUCO no condujera a mejores resultados educativos. En todo caso, un análisis a fondo del programa EDUCO nos indica que lo que se necesita es más atención al contexto en el cual el modelo es implementado, un punto que elaboramos más en lo que sigue.

\section{Discusión sobre las limitaciones prácticas de EDUCO}

EDUCO ha tendido a recibir una atención sustancial por parte de actores políticos e investigadores. De hecho, los investigadores del Banco Mundial dedicaron una increíble cantidad de tiempo y energía a demostrar los impactos positivos de EDUCO. Como se ha señalado previamente, nada menos que siete estudios cuantitativos fueron producidos por esta organización durante finales de los 90 y principios de los 2000, de los cuales todos afirmaban efectos positivos en términos de logros educativos y retención de los estudiantes. Sin embargo, al revisar y analizar detalladamente estos estudios emergen importantes dudas. Respeto los estudios del Banco Mundial, se ha

89 C. Desmond, «EDUCO schools in El Salvador: A democratic tree in a globalized forest?», 2009.

90 Helga Cuéllar-Marchelli, «The cost-effectiveness of EDUCO and traditional public school in rural El Salvador», 2003b, 133.

91 SIMEDUCO, «Ya no estamos dormidos» (San Salvador: Instituto de Derechos Humanos de la Universidad Centroamericana José Simeón Cañas, 2011). 
demostrado en investigaciones previas ${ }^{92}$ que hay buenas razones para poner en duda las conclusiones ofrecidas, debido especialmente a las limitaciones fundamentadas en (a) el diseño del programa (dirigido a comunidades más desfavorecidas y que por lo tanto diferían sistemáticamente de las comunidades sobre las cuales se hicieron las comparaciones en las evaluaciones de impacto), (b) la metodología de los estudios (ya que fueron usados métodos cuantitativos con limitaciones inherentes) y (c) el contexto en el cual el programa fue implementado (ya que muchos programas EDUCO se implementaron en contextos en los que ya se estaban desarrollando modelos gestión comunitaria). Además, en el caso de aquellos estudios en los que los modelos de análisis del Banco Mundial han sido mejorados por otros investigadores, los resultados indican que en realidad el programa suponía efectos negativos sobre los logros de los estudiantes ${ }^{93}$.

Si bien es importante reconocer las limitaciones mencionadas, el presente artículo ha tratado de destacar un área que ha recibido menos atención, esto es, la experiencia de la implementación de EDUCO a nivel local. Muchos aspectos del programa han tendido a pasar por alto en el debate sobre EDUCO, debido a la centralidad de las cuestiones relativas al funcionamiento del programa en términos de resultados mesurables. Se espera que un examen detallado sobre el desarrollo de EDUCO en el plano comunitario contribuya a ampliar la conversación sobre este programa y su percepción. Un modo en el que intentamos realizar esta contribución es a partir de la revisión de literatura, incluyendo artículos que son en gran parte desconocidos, tanto en El Salvador como en la literatura internacional sobre el programa.

Aquí, EDUCO mostró importantes deficiencias en la práctica. Estas deficiencias se refieren a la estructura institucional, con capacidad limitada,

92 D. B. Edwards Jr. y C. Loucel, «El programa EDUCO, las evaluaciones de impacto y la economía política de la reforma educativa global», 2016.

93 Helga Cuéllar-Marchelli, «The cost-effectiveness of EDUCO and traditional public school in rural El Salvador», 2003 b. 
poco personal de apoyo para todas las ACEs y habitualmente con ninguna persona al cargo de las funciones de dirección, ya que las responsabilidades de liderazgo cayeron en los maestros y las familias. En el campo de la participación comunitaria, se reveló que muchos miembros de las comunidades no estaban familiarizados con el programa y que su participación se redujo a contribuir trabajando en la infraestructura escolar (construcción, mantenimiento) y la adquisición de recursos (captación de fondos y materiales).

Respecto a la característica central del programa EDUCO -la gestión de las ACES- múltiples preocupaciones emergen a la práctica. Por ejemplo, las ACEs tendían a estar dirigidas únicamente por dos o tres personas (en vez de cinco miembros, como la política establecía). Además, los miembros de las ACEs normalmente no estaban familiarizados con la documentación y los formularios requeridos para dirigir el programa. De este modo, algunas funciones de las ACEs se trasladaban frecuentemente al profesorado, a los directores (en las escuelas que existía la figura) y/o al personal del MINED, especialmente cuando se trataba de rellenar cuestionarios, gestionar documentos o tomar decisiones. Es significativo subrayar que incluso las decisiones sobre la contratación de profesorado (el elemento central del programa) eran influenciadas por los actores ya mencionados.

Este resultado es mucho más desafortunado cuando uno remarca la situación discriminatoria de los maestros de EDUCO y las pésimas condiciones en las aulas de sus escuelas. Más allá de no tener seguridad laboral - por la naturaleza anual de los contratos de trabajo, renovables de modo discrecional por parte de las ACEs - los maestros a veces se enfrentan con prácticas de contratación sesgadas (por ejemplo, nepotismo) y trato injusto. Todo esto sin tener ninguna vía de reclamación ya que EDUCO no incluyó ningún instrumento o mecanismo para la resolución de quejas o agravios. Legalmente, la gestión empezaba y acababa con las ACEs. Si uno contempla las adversidades a las que se enfrentaban los maestros, junto con el mal estado de las aulas de EDUCO, sería de esperar que el programa presentara efectos 
negativos en los logros educativos de los estudiantes. Además, a la luz de la discusión aquí presentada, parece increíble que EDUCO se haya mantenido como un modelo ejemplar a nivel global por tanto tiempo, dado que presenta una implementación y funcionamiento a nivel local pobre, por lo cual no se puede decir que produzca mejores resultados y que tiene mayores costes por la administración que las escuelas públicas tradicionales ${ }^{94}$.

\section{Reflexiones sobre la historia oculta de EDUCO}

Haciendo una retrospectiva amplia, uno puede ver como en el contexto de El Salvador se combinó, primero, un conjunto de condiciones históricas y estructurales específicas que, luego, con una seria de acciones por parte de ciertos actores institucionales, consolidaron la emergencia de EDUCO como una de las reformas más conocidas de finales de los 90 y principios de los 2000. Más concretamente, el país, afectado por una guerra civil durante los años 80, fue arrastrado hacia la órbita intervencionista de los Estados Unidos a causa de la preocupación que generaba a la Administración Norte Americana la ideología socialista de parte de la oposición. A esto, siguieron los esfuerzos de USAID para (a) dar apoyo a una nueva elite orientada a la exportación (en oposición al presidente populista que entonces estaba en el poder, José Napoleón Duarte) y (b) la creación de intermediarios institucionales a nivel nacional (esto es, FUSADES y FEPADE) que pudieran servir para la incubación y legitimación de una política social y económica de corte neoliberal.

En este contexto, el partido de derechas ARENA ganó las elecciones en 1989 con el apoyo de USAID. Así, el Banco Mundial dio un paso importante para intervenir en el financiamiento y diseño de una estrategia de reforma educativa. Como se ha señalado, este paso del proceso no fue tan

94 B. Edwards, «The trajectory of global education policy: Community-Based Management in El Salvador and the global reform agenda» (próximamente). 
sencillo como uno podría esperar, especialmente debido a que las políticas de mayor preferencia del Banco Mundial (inspiradas con el ejemplo chileno) fueron sustituidas por la experimentación con la gestión escolar comunitaria y el control comunitario de los docentes. Por supuesto, una de las ironías menos conocidas de este caso es que el modelo de EDUCO - caracterizado por la rendición de cuentas de los profesores, por su supuesta eficacia y eficiencia y por el debilitamiento de los sindicatos de profesores - emergió, en realidad, del enfoque del FMLN basado en la solidaridad, el apoderamiento comunitario y la educación popular ${ }^{95}$. En este sentido, otra ironía relacionada se deriva del diseño y el marco de EDUCO: si bien su popularidad y la percepción de su éxito se debe, en parte, al discurso de "apoderamiento" y la "participación comunitaria", la invocación de este lenguaje difuminó el hecho de que a través de EDUCO se creó un sistema escolar de segunda clase que marginalizó amplias partes de la población estudiantil.

Para nuestro propósito, sin embargo, el resultado más destacado es que el Banco Mundial fue capaz - en un contexto de guerra civil, intervencionismo norteamericano y un gobierno nacional debilitado - de financiar, consolidar y luego promover sus preferencias políticas. Dicho de otro modo, el Banco Mundial usó El Salvador como una oportunidad para experimentar con un nuevo modelo de gobernanza. Después de su exitosa implementación, durante la década de los 90 y 2000, el Banco Mundial publicó y difundió ampliamente este modelo a los profesionales del desarrollo

95 Para saber más véase: Asociación de Desarrollo Económico Social, Santa Marta (ADES), «Una Sistematización de la Educación Popular en el Cantón Santa Marta, Cabañas, El Salvador, 1978-2001» (San Salvador: ADES, 2003), M. Cruz, «Orígenes de la educación popular en Chalatenango: Una innovación educativa» (San Salvador: Estudios Centroamericanos, 2004), 897-925, D. B. Edwards Jr., y E. Ávalos, «Santa Marta y el programa EDUCO: Una experiencia de resistencia, adaptación e inversión de la lógica neoliberal» (San Salvador: Universidad Centroamericana José Simeón Cañas, 2015), J. Hammond, «Fighting to learn: Popular education and guerrilla war in El Salvador» (New Brunswick, NJ: Rutgers University Press, 1998). 
y a los gobiernos nacionales como una de las mejores prácticas. A pesar de que actualmente otras reformas - como las alianzas público-privadas - han substituido EDUCO como la superestrella de la reforma de las políticas educativas, el legado de este programa vive en base a la investigación que el Banco Mundial generó.

\section{EDUCO y el diseño de las políticas educativas en la posguerra}

En el periodo de posguerra, hubo un proceso más formal y público respecto el diseño de las políticas educativas que tuvo lugar durante 1993 - 1995. Este proceso tuvo más bien una función simbólica, por lo menos en términos de su relevancia para EDUCO, y como tal tuvo poca influencia en la trayectoria de este programa. Sin embargo, implicó la inclusión de EDUCO como una prioridad clave en los documentos oficiales del MINED, como el Plan Decenal de Educación. Para resumir brevemente, este proceso comprendió: (a) la producción y discusión de una evaluación del sector educativo (durante octubre - diciembre de 1993, financiado por la USAID), (b) talleres promocionales (durante enero de 1994, impartidos por el Instituto de Desarrollo Internacional de Harvard, la Universidad de Centro América, FEPADE y un comité organizador), (c) una Comisión Nacional de Educación Ciencia y Desarrollo (la cual pasó varios meses, durante octubre de 1994 y junio de 1995, desarrollando una visión para la reforma del sistema educativo), (d) un fórum consultivo (en enero de 1995, el cual fue financiado por la USAID y tenía el objetivo de compartir y recibir comentarios con más de 200 representantes de instituciones educativas, tanto en la evaluación del sector educativo como en las orientaciones para la reforma de la educación en general) y (e) la definición de la estrategia para la educación del MINED (publicada en noviembre de 1995, y supuestamente basada en la evaluación del sector, el proceso consultivo y el informe de la Comisión Nacional de Educación). 
Esta estrategia se concretó en cinco objetivos definidos en el Plan Decenal de Educación, los cuales fueron: la mejora de la calidad de la educación; aumentar la eficiencia, eficacia y equidad del sistema educativo; ampliar la cobertura educativa; crear "nuevas modalidades de provisión de servicios"; y "fortalecer la formación de valores humanos, éticos y cívicos" ${ }^{\text {. E }}$ El programa EDUCO fue caracterizado en este Plan como la principal estrategia para aumentar la cobertura educativa del sistema.

Durante estos dos años, se dedicó una enorme cantidad de tiempo y energía en organizar y realizar eventos, desarrollando investigaciones y pidiendo retorno. Sin embargo, después de la revisión de este proceso, es llamativo que el programa EDUCO fuera prácticamente omitido. Apenas se mencionó en la evaluación del sector educativo y no apareció en el informe de la Comisión Nacional de Educación. Ahí donde fue mencionado, por ejemplo en el fórum consultivo, la discusión tendió a concernir sobre aspectos relativos a la mejor incorporación de EDUCO en el MINED, pero no si esta debía ser o no una estrategia central para la provisión y gobernanza de la educación.

Al fin y al cabo, no debemos sorprendernos de que EDUCO se incluyera en el Plan Decenal, ya que este programa contaba con el apoyo de los actores clave dentro y fuera del MINED. Como se explicó anteriormente, la política de EDUCO empezó en la práctica en 1991 y fue el resultado de la promoción y el apoyo de la consultora de UNESCO combinado con los cálculos políticos de parte del MINED y de los representantes del Banco Mundial. Es decir, la Ministra de Educación y el Banco Mundial ya habían decidido que iban a implementar el programa EDUCO como una política del sector educativo, y a tal fin ya habían negociado varios préstamos. El proceso oficial que vino casi tres años después del inicio de EDU$\mathrm{CO}$ no iba a cambiar eso. En otras palabras, el proceso político formal para

96 Ministerio de Educación, «Lineamientos generales del Plan Decenal, 1995-2005» (San Salvador: MINED, 1995), 11. 
incluir EDUCO en los documentos oficiales de la política educativa llego más tarde y sirvió para legitimar, aún más, la política de facto del MINED para conseguir la reforma de la gobernanza educativa.

\section{Conclusiones: EDUCO y la guerra civil}

Al reflexionar sobre las consideraciones expuestas en este ensayo, es necesario destacar que EDUCO emergió con las mismas dinámicas políticas que llevaron al triunfo de ARENA en las elecciones presidenciales de 1989. De este modo, EDUCO puede ser visto como uno de los resultados de las dinámicas políticas promovidas por la USAID durante la década de 1980. Si bien la USAID contribuyo a la creación de la FUSADES y la FEPADE, estas instituciones y sus trabajadores contribuyeron por su parte al desarrollo de EDUCO de modos tanto específicos como generales. Otra conexión que se puede hacer en este sentido, es que así como la reforma económica neoliberal promovida por ARENA tuvo efectos negativos por la economía de El Salvador, también EDUCO tuvo repercusiones negativas para la educación en El Salvador. Es decir, del mismo modo que las reformas económicas de finales de los 80 y los 90 abrieron la economía del país teniendo implicaciones negativas para los pequeños agricultores (entre otros) y para la capacidad del gobierno salvadoreño de protegerse de la economía internacional, también EDUCO debilitó la educación en muchas comunidades. Además de representar un golpe al sindicalismo (en la medida en que los docentes de EDUCO no podían pertenecer a los sindicatos de profesores), EDUCO tuvo efectos muy reales y perjudiciales en la práctica, como se detalló en las secciones que se centraron en la implementación de EDUCO a nivel comunitario.

Al reconsiderar el significado de EDUCO, también es importante plantear algunos comentarios adicionales sobre lo que representó EDUCO 
para las comunidades en áreas controladas durante la guerra por el FMLN. Este es un asunto que normalmente no ha sido discutido. De modo breve, el modelo comunitario del FMLN - teñido de las nociones de solidaridad y conciencia crítica como parte del proyecto de desarrollo socialista - fue transformado por EDUCO, el cual supuso un experimento basado en los principios del neoliberalismo inscritos en nociones mecanicistas de la evaluación docente y la rendición de cuentas. Las comunidades del FMLN fueron particularmente afectadas por EDUCO porque este programa ayudó al gobierno, durante el contexto de posguerra, a incorporar y debilitar dichas comunidades. De hecho, el gobierno aplicó deliberadamente el programa EDUCO a las comunidades del FMLN, las cuales fueron las primeras comunidades a unirse al programa. (Remarcar que la guerra acabó en enero de 1992, un año después de que EDUCO empezara a principios de 1991). Esta incorporación y debilitamiento fue el resultado de un conjunto de factores: Primero, las comunidades del FMLN estaban desesperadas para conseguir recursos; y segundo, el gobierno solo aceptaba dar apoyo educativo en las zonas controladas por el FMLN (como en todas las áreas rurales) a través del programa EDUCO. Significativamente, las comunidades no solo eran requeridas a unirse a EDUCO si querían recibir recursos del gobierno, sino que además tenían que contratar profesores de fuera de su comunidad, ya que los profesores de la educación popular tenían bajos niveles educativos y por lo tanto no cumplían con los requerimientos respecto a las credenciales necesarias para ser contratados en el programa EDUCO. Este requisito fue un golpe duro para la educación popular, así como para toda su visión más amplia del proyecto comunitario.

Para terminar, el punto de vista crítico que se presenta en este artículo sobre la historia y la implementación de EDUCO, no pretende sugerir que debemos alejarnos de la idea de gestión comunitaria de la educación. Más bien, lo que los estudios sobre EDUCO y otras investigaciones previas indican es que debemos extender nuestro análisis sobre la gestión comu- 
nitaria así como los modos por los que la capacidad comunitaria puede ser ampliada. Si bien algún trabajo reciente ha subrayado la posición de los directores de las escuelas en contextos de vulnerabilidad y el rol que pueden jugar a la hora de movilizar los miembros de la comunidad y contribuir a la calidad educativa ${ }^{97}$, también se argumenta que tenemos que pensar en el capital social comunitario de una forma más amplia. En otras palabras, planteamos aquí que los investigadores deben mirar más allá de la escuela en sí misma, para examinar también los procesos, las políticas, las condiciones y las estrategias que pueden reforzar, en un sentido más general, el desarrollo comunitario, el apoderamiento y bienestar de las comunidades, así como su capital social. Con este fin, el legado de la teología de la liberación, de la educación popular y de la experimentación con formas alternativas de autogobierno comunitario (particularmente en las comunidades del FMLN, durante y después de la guerra) se convierten en cuestiones primordiales para una mayor investigación, que expanda esta conversación entorno la educación basada en la gestión comunitaria y el desarrollo comunitario. Más allá de las nociones mecanicistas de la participación comunitaria en la gobernanza escolar, es esencial que los académicos aborden de un modo riguroso las formas más democráticas de organizar, no solo las escuelas, sino también las comunidades en las que están insertas. ${ }^{98}$

\footnotetext{
97 D. DeMatthews, D. B. Edwards Jr. and R. Rincones, «Social justice leadership and community engagement: A successful case from Ciudad Juárez, Mexico» (Educational Administration Quarterly, 2016).

98 Para más referencias ver: D. B. Edwards Jr. And S. Klees, «Participación en el desarrollo internacional y la gobernanza de la educación: Tres perspectivas y tres casos de El Salvador» Revista Latinoamericana de Educación Comparada 5, (2014), 107-12.
} 


\section{REFERENCIAS BIBLIOGRÁFICAS}

Asociación de Desarrollo Económico Social, Santa Marta (ADES). Una

Sistematización de la Educación Popular en el Cantón Santa Marta, Cabañas, El Salvador, 1978-2001. San Salvador: ADES, 2003.

Alvear Galindo,V. La educación en Morazán, El Salvador, durante la guerra civil de 1981 a 1992: ¿parte de una estrategia de supervivencia?. Tesis Doctoral sin publicar. Berlin: Berlin Free University, 2002.

Ávila de Parada, A. y Landaverde de Romero, M. La gestión educativa y el desempeño de centros escolares de la modalidad Educación con Participación de la Comunidad (EDUCO) en El Salvador. Tesis Doctoral sin publicar. San Salvador: Universidad Centroamericana José Simeón Cañas, 2007.

Ayala, R. Evaluación del programa de Educación con Participación de la Comunidad EDUCO. San Salvador: MINED, 2005.

Booth, J., C. Wade and T. Walker. «Understanding Central America». Boulder, CO: Westview Press, 2006.

Bray, M. «Community initiatives in education: Goals, dimensions and linkages with governments». Compare 33, 31-45, 2003.

Conyers, D. «Decentralization: The latest fashion in development administration?» Public Administration and Development, 3, 97-109, 1983.

Cruz, M. «Orígenes de la educación popular en Chalatenango: Una innovación educativa». Revista de Estudios Centroamericanos, 897-925. San Salvador: Universidad Centroamericana José Simeón Cañas, 2004.

Cuellar-Marchelli, Helga. «Decentralization and privatization of education in El Salvador: Assessing the experience International». Journal of Educational Development 23, 45-166, 2003 a.

The cost-effectiveness of EDUCO and traditional public school in rural El Salvador. Tesis Doctoral sin publicar. Columbia:Teachers College, Columbia University, 2003b. 
DeMatthews, D. \& Edwards Jr., D. B., and Rincones, R. «Social justice leadership and community engagement: A successful case from Ciudad Juárez, México». Educational Administration Quarterly, 2016.

Desmond, C. EDUCO schools in El Salvador: A democratic tree in a globalized forest?. International Education 38, 7-28, 2009.

Edwards Jr., D. B. The trajectory of global education policy: Community-Based Management in El Salvador and the global reform agenda. New York: Palgrave MacMillan, próximamente.

Edwards, D. «El concepto del Banco Mundial de la participación en el desarrollo y la gobernanza de la educación: Un análisis de su acercamiento y resultados». Revista Latinoamericana de Estudios Educativos, 13-46, 2014.

Edwards, D. B. y Ávalos, E. Santa Marta y el programa EDUCO: Una experiencia de resistencia, adaptación e inversión de la lógica neoliberal. San Salvador: Universidad Centroamericana José Simeón Cañas, 2015.

Edwards Jr., D. B. and DeMatthews, D. «Historical trends in educational decentralization in the United States and developing countries: A periodization and comparison in the post-WWII context». Education Policy Analysis Archives, 22 (40), 1-36 (2014). Disponible en: http:// dx.doi.org/10.14507/epaa.v22n40.2014

Edwards Jr., D. B. y Klees, S. «Participación en el desarrollo internacional y la gobernanza de la educación: Tres perspectivas y tres casos de El Salvador». Revista Latinoamericana de Educación Comparada 5, $107-$ 121, 2014.

Edwards Jr., D. B. y Loucel, C. «El programa EDUCO, las evaluaciones de impacto y la economía política de la reforma educativa global». Archivos Analíticos de Políticas Educativas, 24 (49), 1-50, 2016. Disponible en: http://epaa.asu.edu/ojs/article/viewFile/2019/1821

Edwards Jr., D. B., Martin, P., and Flores, I. «Education in El Salvador: Past, present, and prospects». Education in México, Central America and the 
Latin Caribbean, Continuum. Ed. C. M. Posner, Chris Martin and Yvonne Martin, próximamente-a.

«Teacher education in El Salvador: Politics, policy, pitfalls». International handbook of teacher education. Ed. C. Wolhuter. Athens: Atrapos, próximamente-b.

Edwards Jr., D. B., Victoria, J. y Martin, P. «Corrientes internacionales, desarrollos estructurales, preferencias nacionales y la implementación de políticas educativas: Hallazgos en El Salvador durante el periodo 1990-2005». Journal of Supranational Policies of Education, 2, 111140, 2014. Disponible en: http://www.jospoegipes.com/Articulos/ VOL2/6_JOSPOE_VOL2.pdf

Eriksson, J., Kreimer, A. and Arnold, M. El Salvador: Post-conflict reconstruction: Country case evaluation. Washington, D.C.: World Bank, 2000.

Gillies, J., Crouch, L., y Flórez, A. Revisión estratégica del programa EDUCO. USAID, 2010. Disponible en: http://www.equip123.net/docs/E2_ REVISION_DEL_PROGRAMA_EDUCO.Pdf

Hammond, J. Fighting to learn: Popular education and guerrilla war in El Salvador. New Brunswick, NJ: Rutgers University Press, 1998.

Leo Grande, W. Our own backyard:The United States and Central America, 19771992. Chapel Hill: University of North Carolina, 1998.

Lindo Fuentes, H. Comunidad, participación y escuelas: EDUCO en El Salvador. Washington, D.C.: World Bank, 1998.

Meza, D., Guzmán, J., and de Varela, L. «EDUCO: A community-managed education program in rural areas of El Salvador». Paper presented at Scaling Up Poverty Reduction: A Global Learning Process and Conference. Shanghai, May 25-27, 2004.

MINED. Servicios educativos a niños pobres Salvadoreños de 0 a 14 años. San Salvador: MINED, 1990.

MINED. Lineamientos generales del Plan Decenal, 1995-2005. San Salvador: MINED, 1995. 
Montero, A. and Samuels, D. Decentralization and Democracy in Latin America. Notre Dame: University of Notre Dame Press, 2004.

Montgomery, T. Revolution in El Salvador: From civil strife to civil peace. Westview: Boulder, 1995.

Orr, R. C. Building peace in El Salvador: From exception to rule. Peacebuilding as politics: Cultivating peace in fragile societies, 153-182. Colorado, USA: Lynne Rienner Publishers, Inc, 2001.

Ramírez, C. «EDUCO inició este mes su ingreso al escalafón». La Prensa Gráfica. Marzo 24, 2007.

Reimers, F. «The role of the community in expanding educational opportunities:The EDUCO schools in El Salvador». Education and development: Tradition and innovation. Equity and excellence in education for development. Vol. 2, 146-162. Ed. J. Lynch, C. Modgil, and S. Modgil. London: Cassell, 1997.

Robinson, W. Transnational conflicts: Central America, social change, and globalization.Verso: New York, 2003.

Rodríguez, J. C. Incentivos a Escuelas y Maestros: La experiencia del «Plan de Estímulos a la Labor Educativa Institucionals en El Salvador. Chile: Universidad de Chile, Facultad de Ciencias Físicas y Matemáticas, Departamento de Ingeniería Industrial. 2003.

Rosa, H. and Foley, M. «El Salvador. Good intentions: Pledges of aid for postconflict recovery». Good intentions: Pledges of aid for postconflict recovery, 113-158. Ed. S. Forman and S. Patrick. USA: Lynne Rienner, 2000.

Segovia, A. «Macroeconomic performance and policies since 1989». Economic policy for building peace: The lessons of El Salvador, 51-72. Ed. J.K. Boyce. Boulder: Lynne Rienner, 1996.

SIMEDUCO. Ya no estamos dormidos. San Salvador: Instituto de Derechos Humanos de la Universidad Centroamericana José Simeón Cañas, 2011. 
Srygley, M. Education in rural El Salvador: A case study on value, quality, and accountability. Unpublished thesis. Maryland: University of Maryland, College Park, 2013.

Winkler, D. Decentralization in education: An economic perspective. Washington, D.C.: The World Bank, 1989.

World Bank. Report and recommendation of the President of the International Bank for Reconstruction and Development to the Executive Directors on a proposed structural adjustment loan in an amount equivalent to US\$7.0 million to the Republic of El Salvador. Washington, D. C.: World Bank, 1991a.

World Bank. Staff appraisal report. El Salvador: Social Sector Rehabilitation Project. Washington, D.C.: World Bank, 1991b.

World Bank. El Salvador: Community education strategy: Decentralized school management. Washington, D.C.:The World Bank, 1994.

World Bank. Strengthening accountability in social service delivery in Central America: The EDUCO school-based management model. Washington, D.C.: World Bank, 2009. 